\title{
Primate viewing
}

\section{Chimpanzee behaviour shows remarkable regional variation.}

\section{The Cultured Chimpanzee: \\ Reflections on Cultural \\ Primatology \\ by William McGrew \\ Cambridge University Press: 2004. 244 pp.

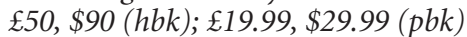

\section{Tetsuro Matsuzawa}

Thirty years ago, two young researchers, William McGrew and Caroline Tutin, visited the Mahale Mountains in western Tanzania. Until then they had been studying wild chimpanzees at Gombe, about $120 \mathrm{~km}$ to the north, but on their first day at Mahale they saw two chimpanzees perform a striking behaviour that was completely new to them. The two chimpanzees were sat on the ground facing one another, and were engaged in mutual grooming. At one point, each fully extended one arm overhead and clasped the other's hand. This created a sort of 'A-frame' postural configuration that revealed the armpit of the raised limb, which was then groomed by the other's opposite hand. The two chimpanzees were in perfect symmetry.

Returning to camp the same evening, McGrew and Tutin mentioned their discovery of the 'grooming hand-clasp' to their host, Junichiro Itani. But Itani was unimpressed: "Don't all chimpanzees do this?" he asked. This was a turning point for McGrew, who at that moment realized that scientists had hitherto been labouring under a simple misapprehension: that chimpanzee social life was the same everywhere.

McGrew and Tutin's pioneering report on the evidence for a 'social custom' in wild chimpanzees was published in 1978, but its importance was not fully recognized until later. At about the same time, fieldworkers on the other side of the continent - at Taï in Côte d'Ivoire and Bossou in Guinea - were making observations about the use of stones by West African chimpanzees. At these sites, wild chimpanzees were using stones to crack open hard-shelled nuts containing edible kernels. In contrast, chimpanzees at Gombe were known to eat the mesocarp, flower, pith, resin and cambium of the oil palm but discard its hard-shelled nut - they lacked the elementary stone technology of their West African relatives.

As increasing numbers of papers were published, the behavioural diversity of chimpanzees in the wild became clearer. McGrew's influential Chimpanzee Material Culture (Cambridge University Press, 1992) was the first book to paint a clear picture of patterns of culture. It showed that different communities of wild chimpanzees have

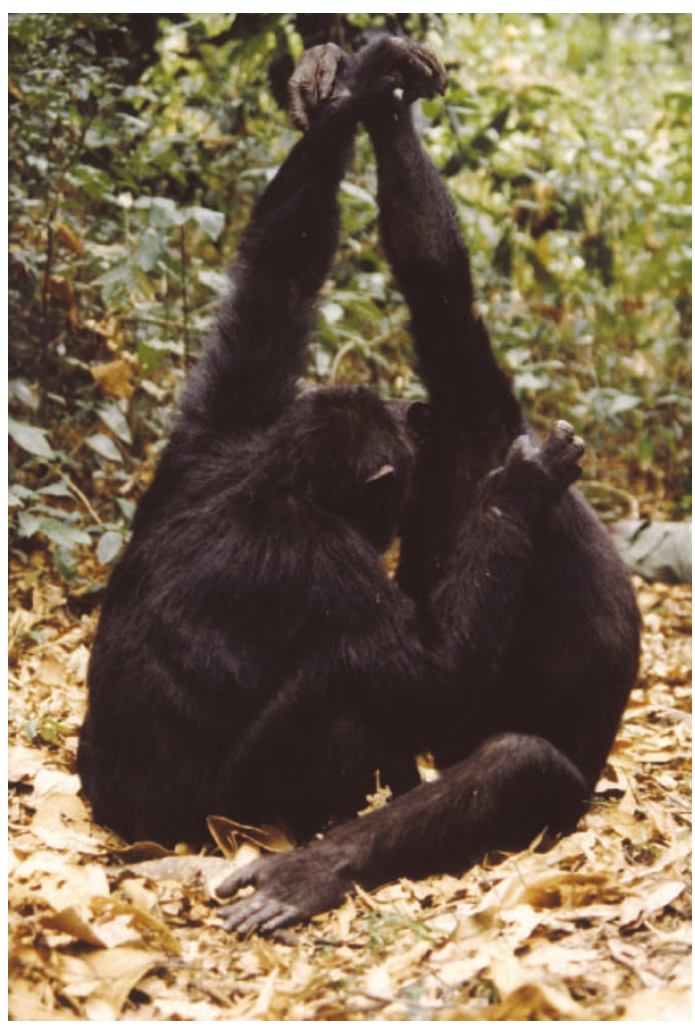

Variety show: chimpanzees at Mahale in Tanzania perform the 'grooming hand-clasp' but those at Gombe do not.

different tools and skills, and that not all of this regional variation can be explained by the demands of the physical and biotic environments in which they live.

The Cultured Chimpanzee is a worthy follow-up, introducing a new discipline called 'cultural primatology'. Its emergence came about as a natural extension of our expanding knowledge of cultural differences among wild chimpanzee communities. The book reviews cultural phenomena in other primate species, as well as non-primates such as fish, birds, mammals and cetaceans. According to McGrew, cultural primatology has a cross-disciplinary nature, having aspects of at least four traditional academic disciplines: anthropology, archaeology, psychology and zoology. Do non-human animals have culture? It depends on the definition. Each discipline asks different questions about culture, and uses different methods to answer them. The Cultured Chimpanzee has 196 pages of text, but contains 469 references - an indication of his dedication to synthesizing the different approaches, covering all the relevant papers about culture in non-human animals, especially chimpanzees.

When trying to sum up the book, three words spring to mind: clear, simple and deep. As McGrew confesses, he is a naturalist (as opposed to an experimentalist), but he pays attention to important issues such as imitation and teaching that have been examined in detail in the lab. He may be an empiricist (and not a theoretician), but he creates a unique framework for drawing scattered data together, thereby clarifying what is known and what is not yet known. His logic and his trains of thought are extremely clear. The text is simple to follow, even for non-English readers, and yet the messages are stimulating, heuristic and reach deep into the heart of the matter. In particular, the chapter entitled "Lessons from cultural primatology" will provide young scientists - future protagonists in the development of this new discipline with plenty of good advice.

McGrew's Chimpanzee Material Culture is already recognized as one of primatology's classic textbooks. This 2004 follow-up should receive similarly wide attention and become another milestone in the study of the evolutionary basis of human culture. However, I would, at some future date, like to see a third book as well, written by the same author on the same topic. As McGrew mentions in the preface, The Cultured Chimpanzee was written just before his first visit to Bossou, Guinea, where a small group of 19 chimpanzees uses stones to crack nuts. As a naturalist and empiricist, coming face-to-face with this behaviour has hopefully provided McGrew with material for new and stimulating insights.

Just as McGrew concludes the book by drawing attention to conservation efforts, I would like to conclude this review by stressing the importance and urgency of protecting the chimpanzees and the forests of Africa. Chimpanzees probably once spanned most of equatorial Africa, including at least 25 countries. They probably numbered more than a million just 100 years ago. Today they occur in 22 countries, and an estimate from the World Conservation Union (IUCN) in 2003 put their numbers in Africa at between 172,700 and 299,700. This sudden decrease is linked to various human activities, such as deforestation, poaching and trading in bushmeat, as well as the transmission of diseases. For example, the Bossou community lost 5 of its 19 members to a contagious respiratory disease at the end of 2003. Similar stories are taking place all over Africa. Truly intense 
efforts are necessary on our part to prevent the extinction of the cultural variation among chimpanzee communities that we have so recently begun to uncover.

Tetsuro Matsuzawa is at the Primate Research Institute, Kyoto University, Kanrin,

Inuyama-city Aichi 484-8506, Japan.

\section{Science in court}

\section{Laws of Men and Laws of Nature: The History of Scientific Expert Testimony in England and America by Tal Golan \\ Harvard University Press: 2004. 336 pp.

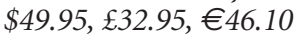

\section{Sheila Jasanoff}

Change one word - write 'trials' in place of 'laws' - and this appealingly readable book would just as appropriately be titled Trials of Men and Trials of Nature. For trials are the stuff of Tal Golan's engaging narrative as he briskly guides his readers through some of the formative moments in a century or so of scientific expert testimony in English and American common law. Men's wits and character are on trial throughout these cases, as experts from varied fields vie to position themselves, their skills and their specialist knowledge at the service of the courts. Nature, too, is often on trial, for the outcomes in the cases that Golan skilfully dissects usually turn on who is right about the way the world works, whether in explaining the silting up of a harbour on the North Sea coast of Norfolk, distinguishing human from animal blood, displaying an X-ray picture of a badly set bone, or diagnosing, through bodily measurements, the likely truthfulness of a witness's testimony in a murder trial.

On one level, Golan's well-chosen selections from the annals of nineteenth-century litigation confirm contemporary prejudices about the relationship between science and law. As in most bad marriages, encounters between the two professions seem unavoidable and yet are sources of profound miscommunication. Since the early days of the Industrial Revolution, there has been no issue so arcane, nor claim so untenable, that an expert cannot be found to help defend it in court. Experts are available for hire in cases ranging from disputes over land use and environmental degradation to criminal identification, medical malpractice and the insanity defence.

But more knowledge does not necessarily mean more illumination. The common law's adversarial genius can divide entire communities of knowledge-holders into opposing camps, each seemingly more interested in its side winning than in arriving at the truth. The notion of science as a disinterested factfinding practice flies out of the courtroom window as floods of expert testimony frustrate judges, confuse juries and make trial outcomes increasingly unpredictable. With experts dominating litigation, laws — natural or human-made - seem less and less relevant to dispensing justice.

Golan on the whole shares the sense of deepening crisis that has gripped AngloAmerican courts since the advent of professional expert testimony. "Alas," he repeatedly exclaims, as he recounts one story after another in which unresolvable battles between partisan experts took over from any impartial attempt to discern the facts of the case. As a historian, Golan is not primarily concerned with solutions, but he does not hide his yearning for a more orderly process in which judges would proactively scrutinize, and perhaps exclude, expert claims, while juries would be selected on the grounds of technical competence rather than generic civic capacity. In this spirit, he approves of the US Supreme Court's 1993 decision in the case of Daubert v. Merrell Dow Pharmaceuticals, a lawsuit over birth defects allegedly caused by the drug Bendectin, which roundly affirmed the duty of federal judges to act as gatekeepers in relation to expert testimony. Judges, the Daubert case declared, should screen expert evidence in accordance with scientists' criteria for determining whether proffered testimony is based on reliable theories and methods. Judges, in short, were asked to think like scientists - and, in so doing, to keep unreliable evidence away from overly credulous juries.

Unfortunately, as Golan's book demonstrates, the problem of expert testimony is too complicated to be solved through the simple expedient of substituting judges for juries. The historical cases impressively reconfirm a point often made by scholars of science studies: the science that courts need, along with the methods for generating it, frequently evolves under the prod of litigation, as part and parcel of the adversary process. Courts in technology-intensive societies are as much agents for producing new knowledge as sites for applying what is already known. Facts are generated, often under severe material and temporal constraints, to fill in gaps in available knowledge and to address the uncertainties of actual cases. Judges, then, may go seriously astray in excluding such evidence because it does not meet the standards of established science. Indeed, because Daubert-like challenges tend to favour corporate defendants more than plaintiffs, exclusion-minded judges may turn out in practice to be thinking more like corporations than like disinterested scientists.

What will happen if the law's dependence on expertise intensifies still further? Golan hopes that salvation will come from within the legal system - and in an unexpected way his wish may be granted. The trial itself may gradually yield to methods of dispute resolution that turn less on the theatrics of the adversary process. Litigation statistics in the United States suggest that trials are becoming a thing of the past, a consequence no doubt of spiralling costs, of which expert testimony is a not inconsiderable fraction. But are backroom bargains, out-of-court settlements and sealed court records desirable substitutes for litigation? This is a question that those committed to both truth and justice may reasonably ask.

Sheila Jasanoff is professor of science and technology studies, John F. Kennedy School of Government, Harvard University, Cambridge, Massachusetts 02138, USA.

\section{Sizing up the world}

\section{Measurement Theory and Practice: The World Through Quantification}

by David J. Hand

Hodder Arnold: 2004. 320pp. £45, \$60

\section{Stephen Senn}

Measurement theory provides a similar touchstone in science to linguistic theory in philosophy. Some see it as fundamental, others as trivial. Most scientists regard it as a distraction, as they seek to theorize and measure, but not to theorize about measurement. It is surprising how many statisticians are largely indifferent to the nature and purpose of measurement. To be sure, there are many statistical theories of errors in measurement, and plenty about probability, but these are not the same as theories about measurement itself. Statisticians have

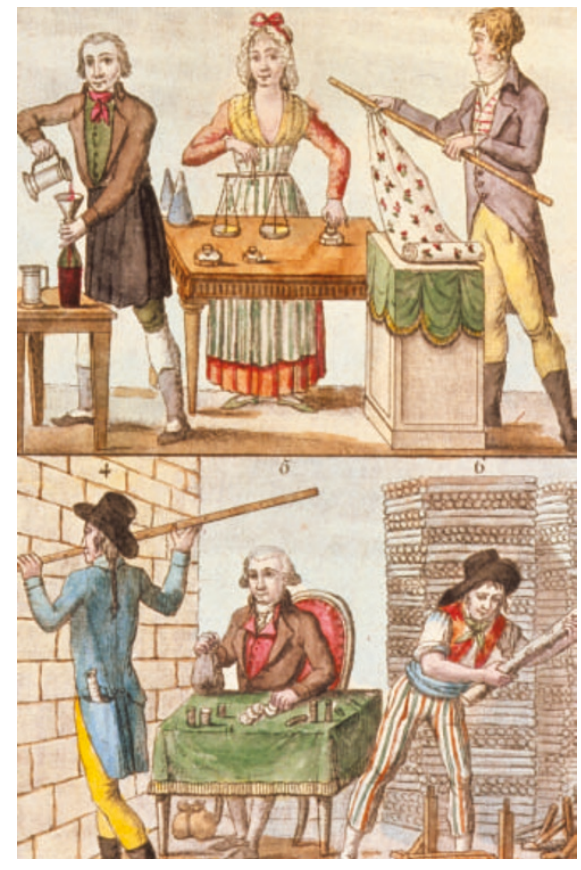

A measured approach: France adopted the metric system in the late eighteenth-century. 